\title{
Research rigor and the gap between academic journals and business practitioners
}

\author{
Eva Perea \\ Universidat Abat Oliba \\ CEU Barcelona \\ Barcelona \\ Spain \\ email: epeream@uao.es \\ Malcolm Brady \\ DCU Business School \\ Dublin City University \\ Dublin 9 \\ Ireland \\ email: malcolm.brady@dcu.ie
}

\begin{abstract}
- Purpose: This paper examines the engagement of business practitioners with academic business research. The main purpose is to assess whether there is a gap between academic research and business people, and, if so, how to bridge this gap.

- Design/methodology/approach: Over 150 senior business practitioners were surveyed, in order to capture their views on the usefulness of academic research to them in their roles as practicing managers. Survey questions covered both their current access and reading of business related publications and what the ideal academic business journal should be, in terms of access and contents.

- Findings: Academic journals are not very well known among business professionals. If these professionals could choose, they would like academic journals to be written by experienced business people, to contain business cases and to be accessible on line. Existing academic business journal 'repositories', such as Google Scholar, are not mentioned in the survey results.

- Practical implications: The findings indicate that potential solutions to bridge the gap between academic journals and business practitioners should not be overly complicated to implement, and would greatly help bring these two communities closer, with mutually enriching results.

- Originality/value: This article takes a very pragmatic view of the gap between academic journals and business practitioners, and seeks to assess this gap in terms of how it can be bridged on an everyday basis, rather than take a theoretical approach. It begs for the definition of actionable next steps.
\end{abstract}

Keywords: Academic, Research, Rigor, Relevance, Business, Practitioner, Research-practice gap

\section{Introduction}

There is much criticism of the disconnection between the research activity of business schools and the real world of business (Starkey and Madan, 2001). Business school research is seen as an 'insulated and self-serving activity on the part of both school leadership and individual scholars' with business schools becoming a 'paper production function' (Tsui, 
2015). It is suggested that business schools have followed the model of the sciences, increasingly measuring themselves primarily on the rigor of their scientific research (Bennis and O'Toole, 2005). However as this research becomes less grounded in business practice it is becoming less and less relevant to practitioners (Bennis and O'Toole, 2005). Paradoxically, practicing managers play little part in the complex process of paper production and evaluation where the main players are academic writers, journal editors, and paper and school ranking agencies (Tsui, 2015).

In addition, with the move towards greater research intensiveness on the part of business schools, academics entering business schools in recent years are more likely to have come up through the university ranks to doctoral level and less likely to have business experience. Many have no experience of business at all and no experience of organizations other than universities. This is in contrast to previous eras where academics often entered business schools after a number of years of experience in industry and were likely to complete their doctorates after they entered academia. It is in great contrast to the early years of business schools where lecturers largely came from industry and had relatively little academic experience. It is therefore likely that younger academics with doctoral degrees but without industry experience will increasingly produce research that will be more and more directed at fellow academics, research that will be increasingly more rigorous from a methodological point of view. An academic reward system that places emphasis on research will tend to further foster rigorous research activity directed at other academics. The danger is that this research will become increasingly less relevant to practitioners and to the business world that these same academics observe.

This paper examines the engagement with academic business research by business practitioners in two countries: Spain and Ireland. It reports on the results of a questionnaire distributed to over 150 senior business practitioners capturing their views on the usefulness of academic research to them in their roles as practicing managers.

\section{Business school research}

Business schools place increasing emphasis on their research. There is evidence from the literature that academic research has significant impact on the standing of the institution but little impact on the practice of management. With respect to the latter, Mintzberg (1996) argues that business school teaching is divorced from the reality of business practice. With respect to the former, Armstrong and Sperry (1994) found a correlation between the prestige of a business school and the impact of that school's research. One justification made in support of research is that it enhances teaching; however a meta-analysis of 58 studies found zero correlation between research productivity and teaching effectiveness i.e. productivity in research neither enhances nor detracts from teaching (Hattie and Marsh, 1996). They conclude that 'the common belief that research and teaching are inextricably entwined is an enduring myth. At best, research and teaching are very loosely coupled' (p.529).

Pfeffer and Fong (2002) suggest that business education is as much about social networking as it is about knowledge gain. They point out that students 'see little connection between what is important and what is being taught' in business schools and suggest that there is a 
disconnection between the skills required by business and what is taught to students. They suggest that there is a greater degree of separation between business schools and the profession they serve than exists in other professional schools such as law, medicine, social work, engineering and architecture. Pfeffer and Fong (2002, p.86) also suggest that the connection between business schools and the profession of management 'has diminished over time'. Their research suggests that business academics have had only a modest influence on management practice compared with the influence of other writers, for example non-business academics, journalists and CEOs.

There exists a considerable literature on the rigor-relevance gulf and how it can be bridged (see Kieser et al. (2015) for an extensive review). The optimistic view is that academic scholars can increase the likelihood of advancing knowledge relevant to practice if they interact, collaborate and forge partnerships with practitioners (Panda and Gupta, 2014). Academic journals targeted at practitioners - bridging journals - are a mechanism for achieving this (Birkinshaw et al., 2016); including practitioners as stakeholders in the research process is another (Starkey and Madan, 2001). Huff (2000) advocates a mode 1.5 approach to research, intermediary between mode 1 - pure scientific research that may be less relevant to practice - and mode 2 - transdisciplinary application based research at which business organizations or consultancy firms have a competitive advantage over business schools. Considering management research as performative - enacting change - as opposed to descriptive may increase its appeal to practitioners (Abrahamson et al., 2016). George (2016) suggests that management scholars should emphasize the significance, novelty, actionability and curiosity value of their research in order to improve its impact on managerial practice and policy. Tartari et al (2014) found that researchers are motivated to engage with industry if their departmental peers also do so. However, Bartunek \& Rynes (2014) point out that the gap is not simply to do with research relevance but is also to do with the differing logics, world views, time dimensions and communication styles of academics and practitioners and this tension must be taken into account when targeting research at practitioners; Davis (2015) suggests that the appropriate target of our research may be neither 'each other' nor practicing managers but society more broadly. Iniguez De Onzono \& Carmona (2016) remind us however that 'reward follow' is at the root of the gulf problem: academics are rewarded for pleasing other academics, not for meeting the needs of practitioners; they argue that the reward system must be changed for the gap to be bridged.

\section{The danger of research with increasing rigor but decreasing relevance}

Given that business schools are becoming more research oriented and their research more rigorous with a resulting increase in the separation of business schools from the profession of management, we suggest some propositions: Managers do not know or are not close to academic journals; Managers have preconceived ideas about 'academia'; Academic journals do not answer the needs of businesses; Writers of academic journals have little or no business experience; Business people's needs for information could be tackled by academic journals should they change the approach regarding vocabulary, topics and dissemination; The existence of academic journals is not publicized.

We now attempt to turn these questions into researchable propositions: 
The increasing emphasis on research is leading to increasing doctoral level recruitment into business faculties.

The increasing emphasis on research is leading to fewer people with business experience being recruited into business faculties.

Less business experience among business academics may result in academic outputs that are less relevant to the world of business.

More academic experience among new business academics may result in academic outputs that are more relevant to the world of academia.

Academic outputs that are less relevant to the world of business may result in reduced interest in academic output among business professionals.

\section{Methodology}

In order to measure the existence and extent of the gap between business school research and management practice, we conducted a survey of business practitioners to understand: what kind of professional publications managers read; if they are aware of academic journals; what the ideal academic journal would be like; what subjects they would be interested in seeing covered; and finally, suggestions to make academic journals more appealing to business professionals.

To better understand and assess the suspected gap between 'business academic papers' and their potential readership from the world of business, a sixteen question survey was designed and distributed to approximately 200 business practitioners. For the sake of this paper, it was decided to focus on those questions which help us understand the current view business practitioners have of academic journals and what academic journals should be like in their dream world. A total of 156 questionnaires were completed between May 12th and July 28th 2016, and afterwards analysed.

Fairly balanced in terms of gender ( 58 per cent male) and age (50 per cent below 40, 48 per cent between 40 and 60) (see figures 1 and 2), the respondents were overwhelmingly university educated (87 per cent) and 60 per cent had over 15 years' working experience. Most respondents held positions of middle or top management in their companies (75 per cent) and came from a broad selection of business areas, sales and marketing being slightly overrepresented.

Figure 1: Respondents by Gender 


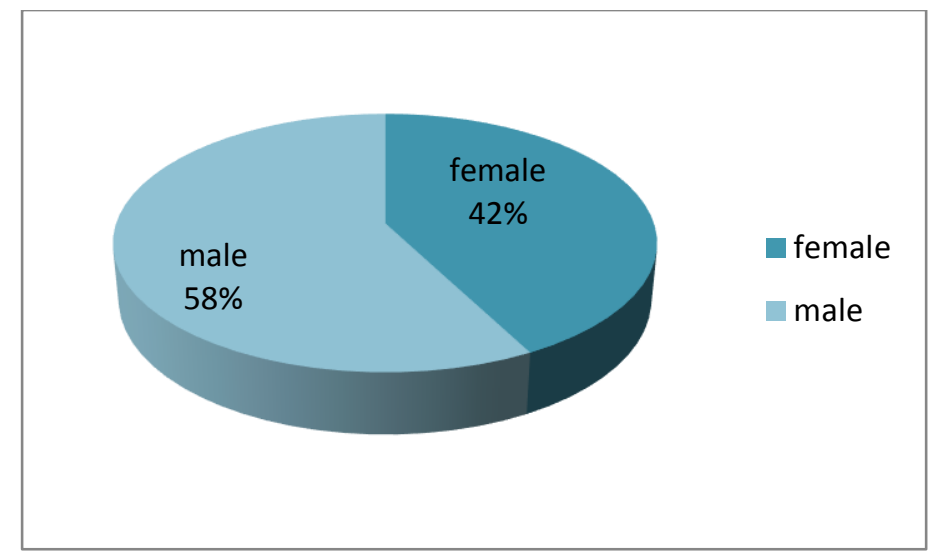

Figure 2: Respondents by Age

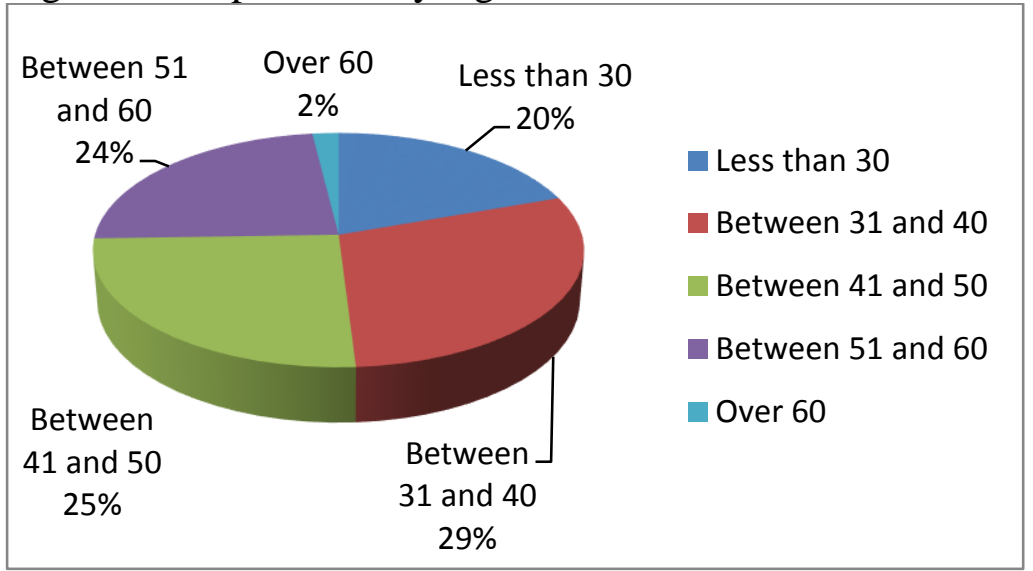

Source: Own Survey

\section{Findings}

Practically all the persons who participated in the survey declared that they read some sort of publication with only two out of 156 not reading any professional publication at all. The most popular publications are 'Daily newspapers' and 'Sector specific newsletters', with about 5657 per cent of the respondents. They are followed by 'Magazines' (half of the respondents) and 'Management books' with 38 per cent (see figure 3).

Figure 3. Kind of professional publications read by business people 


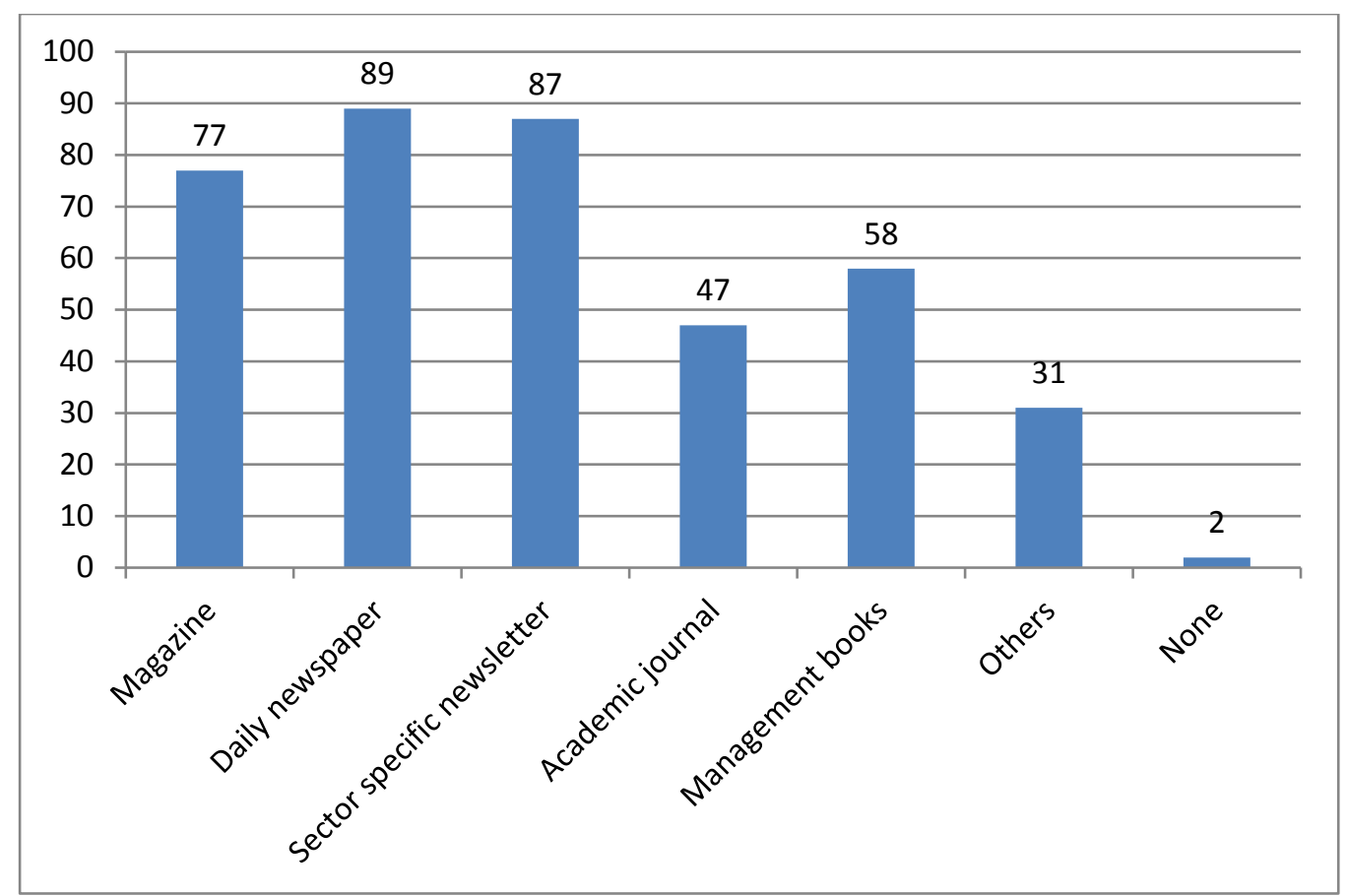

Source: Own Survey

Regarding the frequency with which respondents read business articles, most persons declared that they read 'Once a week' (44 per cent) and 'Daily' (33 per cent), which shows that professionals are very interested in reading contents about business (see figure 4). It can be stated therefore that business people do read and are keen on business knowledge: 78 per cent of them actually read at least on a weekly basis.

Figure 4. How often do practitioners read business articles

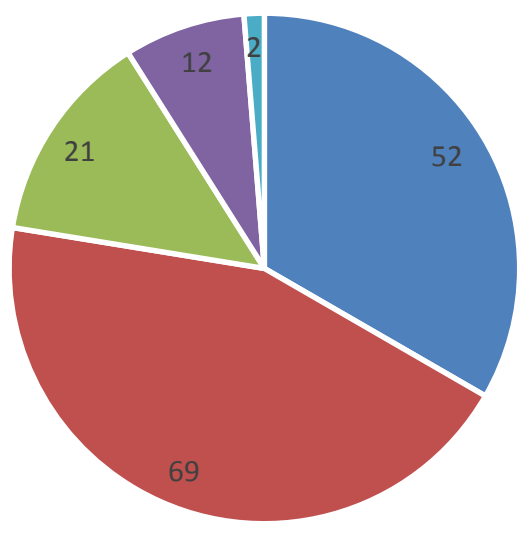

- Daily $\quad$ Once a week $\quad$ Once a month $\quad$ A few times a year $\quad$ Never

Source: Own Survey

Respondents are afterwards asked whether they are familiar or not with academic journals related to their sector of activity. Only 40 per cent declare to be familiar, while 60 per cent do 
not know them at all (see figure 5), which shows that academic journals are not very popular amongst business professionals, even when they have a high level of studies and several years of working experience. Moreover, in many respondents' minds, there appears to be a certain confusion as to what an academic journal actually is, and many would consider a professional publication (for example, 'Pulp and Paper International' or 'Moneda y Crédito') to be an academic journal.

Figure 5. Familiarity of practitioners with academic journals

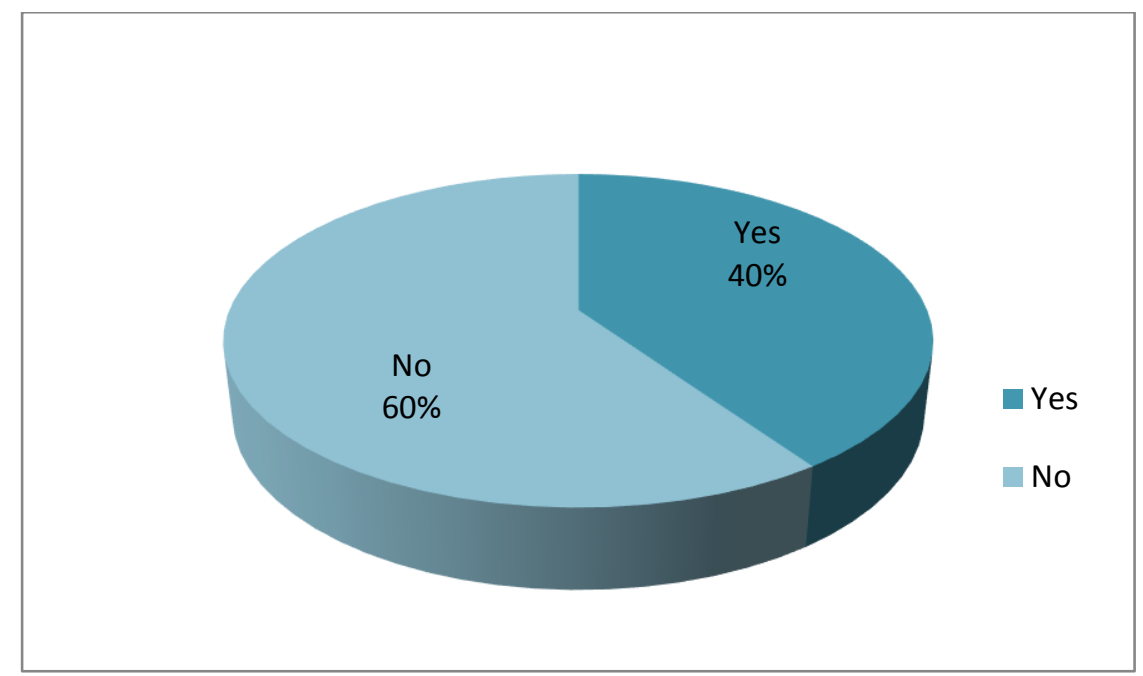

Source: Own Survey

Having established the low level of familiarity with academic journals, respondents are asked to explain what that ideal journal would be for them. According to the business practitioners who were surveyed, the characteristics of an ideal academic journals should be (1) accessible on line, (2) written by experienced business people, and (3) should contain business cases: those are very clearly the three main requirements journals should satisfy according to practitioners (figure 6). They may focus on sector specifics or cover general business knowledge: there is less agreement on this point.

On the other hand, the three factors that practitioners value the least are that: (1) they are free of charge (so apparently, they would be willing to pay for practical knowledge) (2) they contain theoretical research, and (3) they are written by renowned academics (figure 6). There seems to be a very clear preference towards practical experience rather than theoretical knowledge.

Figure 6. The ideal academic journal from a practitioner point of view 


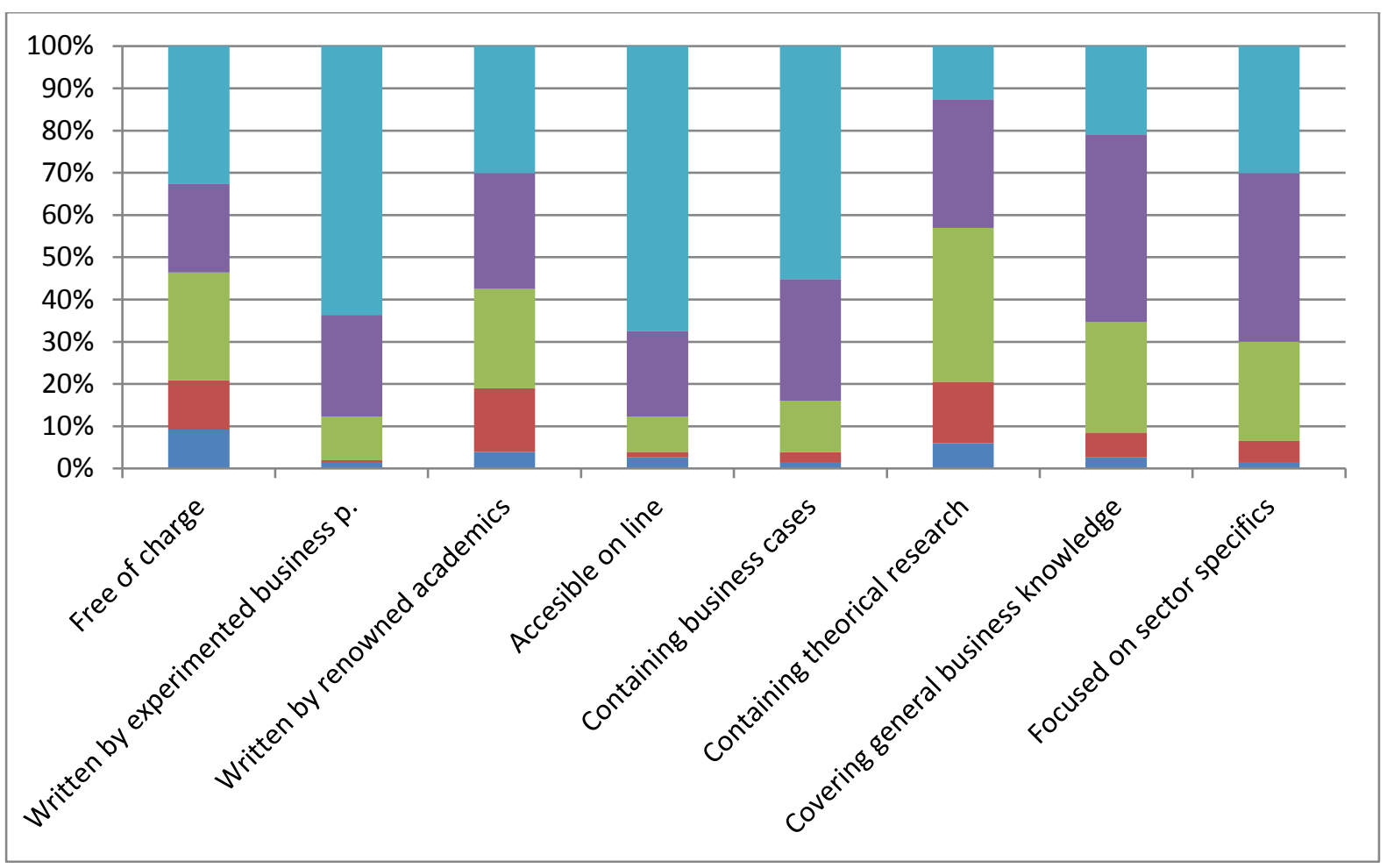

Key: The lower segments represent lower importance; upper segments, higher importance. Source: Own Survey

Respondents were asked what, from a practitioner viewpoint, the ideal focus of an academic journal should be on. The findings showed that most important areas of focus are: (1) practical cases, (2) best practice sharing and (3) dissemination of new management ideas (see figure 7). Least focus should be placed on: (1) student education and (2) academic research. However, practitioners also regarded building bridges between academia and practice as an important focus of academic journals.

Summarizing, the majority of respondents expressed a wish to have "free and easy access to practical, simply written, 'best practice sharing' papers that can help be more efficient in their jobs". In many respondents' minds, there appears to be confusion as to what an academic journal actually is, and many would consider a professional publication to be an academic journal. The majority are not aware of the existence of academic journals related to their sector of activity.

Figure 7. Practitioner view on focus of academic journals 


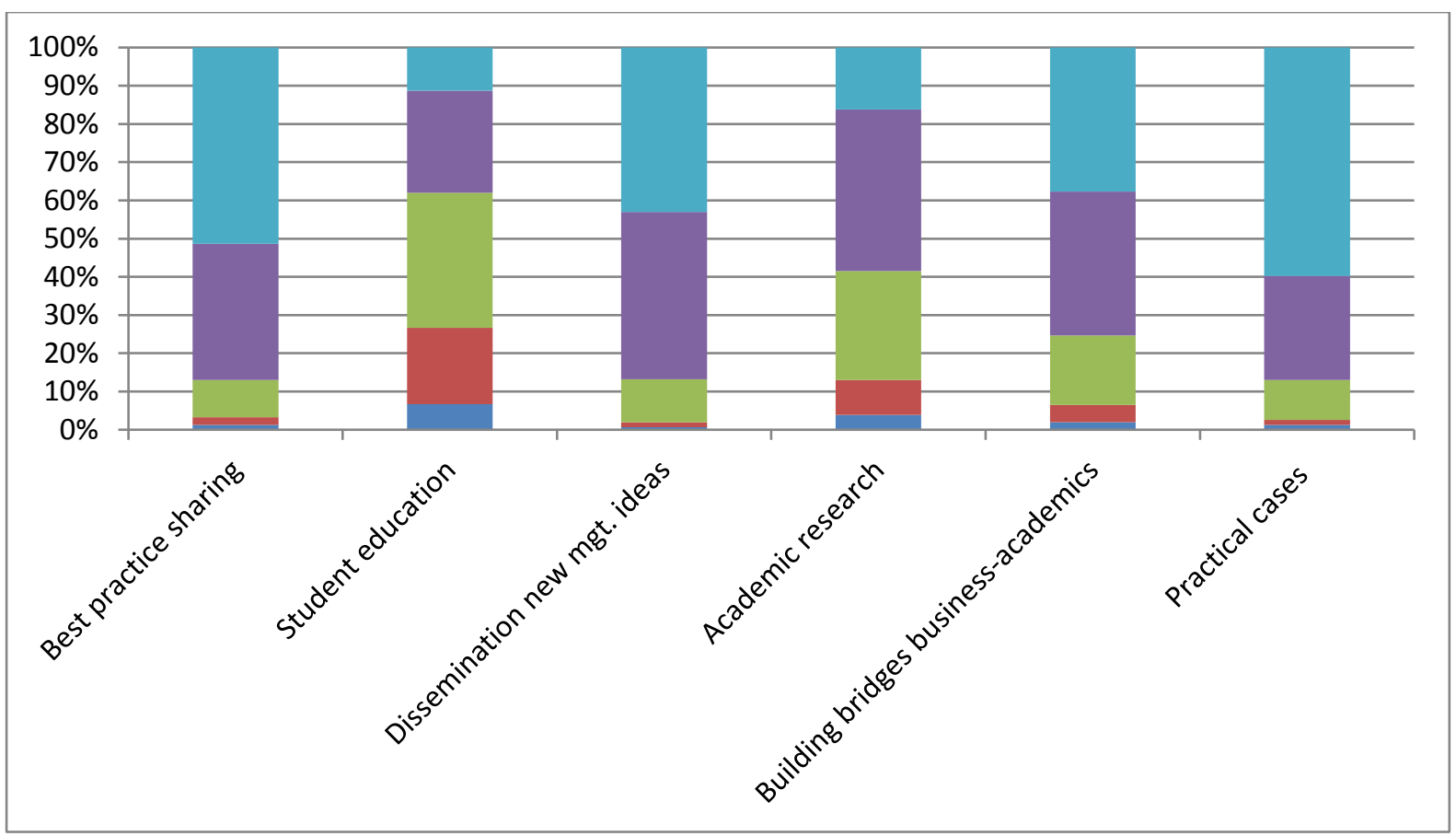

Key: The lower segments represent lower importance; upper segments, higher importance. Source: Own Survey

At the end of the interviews, several general questions were asked of business professionals regarding their opinion on academic journals. From their answers, it can be stated that academic journals are not very well known by these professionals (only about 20 per cent know them well or very well). Only one third of the respondents believe that academic journals offer relevant or very relevant information for business leaders. While this seems to be certainly quite negative, there is hope: almost 60 per cent of the respondents would like to know more about academic journals.

More detailed findings show that: more women than men believe that journals should focus on best practice sharing; more young people below 40 years old than people over 40 would be interested in seeing Finance and Accounting topics; top managers prefer academic journals to focus on best practice sharing and dissemination of new management ideas, more so than middle managers or employees; managers with higher education levels prefer that academic journals are written by renowned academics (which is not the case in lower education levels). Apart from the ones mentioned above, no significant differences have been found between independent variables (gender, age, number of years at work, education level, position in the company) and the preferences for academic journals. Here are a few key selected quotes from respondents' comments:

- "should be readable by the layman"

- "accessible online"

- "case studies"

- "partner with experienced business leaders"

- "should apply to business"

- "exec summary free of charge, full article on per event fee" 
One interesting observation is that the existence of Google Scholar is not mentioned once by any respondent. Leaving aside the pricing aspect and the issue of adapting the writing style to a business readership, tools such as Google Scholar would appear to answer all other requirements regarding accessibility. One possible additional issue which doesn't appear as clearly identifiable from the survey results is that business people often expect reading material to 'land' on their desks, rather than have to look for it. Availability of information does not mean access to, and use of, information.

Contrast statistical analysis has been carried out: Descriptive statistics; Non parametric tests and contrast analysis: Kolmogorov-Smirnov, Mann-Whitney, Kruskal-Wallis.

What would be the ideal academic journal for business people: best valued characteristics:

\begin{tabular}{|l|l|l|l|l|}
\hline Order & Best valued characteristic & $\mathrm{n}$ & Average & $\mathrm{S}$ \\
\hline 1 & Accessible on line & 154 & 4.49 & 0.902 \\
\hline 2 & Written by experienced business people & 154 & 4.48 & 0.810 \\
\hline 3 & $\begin{array}{l}\text { Cases of practical application for businesses + } \\
\text { business cases }\end{array}$ & 154 & 4.43 & 0.831 \\
\hline 4 & Great leaders sharing experience & 151 & 4.38 & 0.831 \\
\hline 5 & Best practice sharing & 154 & 4.34 & 0.834 \\
\hline
\end{tabular}

Source: own research

These five characteristics can be summarized in two: articles that can be found on line, portraying practical information based on real experience - that is what business people want. Contrast statistics

According to the results shown by contrast statistics carried out, some conclusions can be drawn:

Women believe that journals should focus on best practice sharing, more so than men $(\mathrm{z}=-$ 2.050; $\mathrm{p}=0.040$ );

Young people, below 40, would be more interested in seeing Finance and Accounting covered than older people over $40(x 2=10.363 ; \mathrm{gl}=4 ; \mathrm{p}=0.035)$;

Top managers find that academic journals should focus on best practice sharing $(x 2=7.061$; $\mathrm{gl}=2 ; \mathrm{p}=0.029)$ and dissemination of new management ideas $(x 2=6.811 ; \mathrm{gl}=2 ; \mathrm{p}=0.033)$, more so than middle managers or employees;

When the education level obtained is highest, the fact that academic journals are written by renowned academics is more valued, which is not the case in lower education levels $(x 2=9.684 ; \mathrm{gl}=3 ; \mathrm{p}=0.021)$.

\section{Discussion}

It may well be the case that this separation of the observer from the world observed is greater for business school academics that for academics from other disciplines. Firstly, businesses do not like their internals to be observed, written up and published to the wider world. The materials within the business may be commercially sensitive. Businesses may not wish to allow the resources behind their competitive advantage to be observed, recorded, codified, documented or published (Donaldson, 2002, pp.99-100). It can therefore be difficult for 
academic observers to gain access to the world that they wish to observe. Academics may have no alternative but to use publicly available information: industry reports and company annual reports. These however are but a shadow of the real firm.

Secondly, business academics may be more divorced from the field they observe than are academics from other fields. For example, historians observe traces from the past and use these to deduce the nature of past events. Historians train their students to do the same thing and the students go out into the field and work with traces of the past. Business school lecturers increasingly train their students based on a partial understanding of the field they observe, and a field they have only partially observed. However those students go out into the full field - that observed by the academic and that not observed - and not a partial field. It may be that training students based on partial knowledge will not fully equip them for dealing with the full field when they arrive in it.

This poses a dilemma for business schools. Increasing research rigor is good for international research reputation and standing (Economist, 2007) and a goal of business school research is to increase the school's prestige (Pfeffer and Fong, 2002). However, decreasing relevance may lead to business schools becoming viewed as an expensive luxury. Business schools, particularly at the top end, have largely gone the route of pursuing increasingly rigorous research. The question is: will this lead to business schools increasingly living inside an academic bubble with the consequent danger of becoming less relevant to industry and society. Society may take the view that academic research within business schools is largely an activity whereby a closed group of people talk only to themselves: 'an incestuous, closed loop' (Hambrick, 1994:13).

\section{What are the implications for business schools?}

Business schools are educating students to go into businesses or to take up management or other professional positions in industry. As lecturers have less and less practical understanding of the world into which they are sending their students, problems must arise. In other disciplines lecturers will have an understanding of what it is to work in the field. A historian knows what it is like to work as a historian; a chemistry lecturer knows what it is like to work as a scientist. It is arguable whether or not a business academic knows what it is like to work as a business man or manager. The exception to this may be the more technical fields such as finance.

We have therefore on the one hand a profusion of academic journals publishing papers which are seldom read by business leaders and, on the other, a profusion of business professionals eager to have access to journals and papers, as long as they are written in plain language and their contents can be turned to practical business use. The challenge is, as one respondent put it, to "bridge the gap" between the two worlds. This assumes of course that authors of academic papers wish to be read by business practitioners, and not only by other academics. To bridge the gap we suggest focus be given to the key challenges identified by this survey:

- Publicizing the existence of academic journals;

- Focusing journal articles around case study research; 
- Encouraging academics to co-write with business practitioners;

- Ensuring that papers directed at practitioners are written in plain language;

- Ensuring that contents are directly useful to practitioners i.e. are practical, innovative, relevant, implementable and inform best practice;

- Making access to journals easily available and at low cost.

However, if government continues to reward research excellence in business schools as measured by highly cited academic journals, and university recruitment and promotion schemes continue to align with this policy, then it is unlikely that significant changes will be observed soon.

This research has some limitations. Care should be taken in generalizing from the results as it is based on a limited quantitative survey of managers from two countries. Further work is needed to confirm the results for other countries. It may be worthwhile to carry out further research to considering if the findings are modified by country, industry sector or firm size. Further, qualitative, research may provide a more in depth and nuanced view of the needs and motivations of managers regarding use of academic materials. It would also be interesting to survey academics for their perspectives on the relevance of their work to the world of practice.

\section{Conclusion}

There is a gap between two worlds: the academic journal on the one hand, and industry on the other. Business school research has been criticized for its disconnection from the world of business practice; research papers produced by business schools are criticized for having little or unclear value for business managers. This study found that the gap in the perception of academic research between academics themselves and their potential readership from the world of business continues to exist. However this study also found that there remains a thirst for academic knowledge among practitioners. The challenge remains for business school academics to bridge the gap between the two worlds, or run the risk of society forcing the issue. This gap may be difficult to bridge without first tackling the academic reward system.

\section{References}

Abrahamson, E., Berkowitz, H, \& Dumez, H. 2016. A more relevant approach to relevance in management studies: an essay in performativity. Academy of Management Review, 41(2):367-381.

Bennis, W. \& O'Toole, J. 2005. How business schools lost their way. Harvard Business Review, 83(5):96-104.

Bartunek,J. M., \& Rynes,S.L. 2014. Academics and practitioners are alike and unlike: The paradoxes of academic-practitioner relationships. Journal of Management, 40(5):1181-1201.

Birkinshaw, J., Lecuona, R. \& Barwise, P. 2016. The relevance gap in business school research: Which academic papers are cited in managerial bridge journals? Academy of Management Learning \& Education, 15(4):686-702.

Davis, G. F. 2015. Editorial essay: What is organizational re-search for? Administrative Science Quarterly, 60:179-188 
Donaldson, L. 2002. Damned by our own theories: Contradictions between theories and management education. Academy of Management Learning \& Education, 1(1):96-106

Economist. 2007. Practically irrelevant? What is the point of research carried out in business schools? The Economist, Aug 28 ${ }^{\text {th }}$. http://www.economist.com/node/9707498

George, G. 2016. Management research in AMJ: Celebrating impact while striving for more. Academy of Management Journal, 59(6):1869-1877.

Hambrick, D. 1994. What if the academy actually mattered? Academy of Management Review, 19(1):11-16.

Hattie, J. \& Marsh, H.W. 1996. The relationship between research and teaching: A metaanalysis. Review of Educational Research, 66(4):507-542.

Huff, A. 2000. Changes in organizational knowledge production. Academy of Management Review, 25(2):288-293.

Iniguez De Onzono, S. \& Carmona, S. 2016. The academic triathlon - bridging the agora and academia. Journal of Management Development, 35(7):854-865.

Kieser, A., Nicolai, A., \& Seidl, D. 2015. The practical relevance of management research: Turning the debate on relevance into a rigorous scientific research program. Academy of Management Annals, 9:143-233

Panda, A. \& Gupta, R. 2014. Making academic research more relevant: a few suggestions. IIMB Management Review, 26(3):156-169.

Pfeffer, J. \& Fong, C.T. 2002. The end of business schools? Less success than meets the eye. Academy of Management Learning and Education, 1(1):78-95.

Starkey, K. \& Madan, P. 2001. Bridging the relevance gap: Aligning stakeholders in the future of management research. British Journal of management, 12(special issue):S3-S26.

Tartari, V., Perkmann, M., \& Salter, A. 2014. In good company: the influence of peers on industry engagement by academic scientists. Research Policy, 43(7):1189-1203.

Tsui, A. 2015. Reconnecting with the business world: Socially responsible scholarship. EFMD Global Focus, 09(01):36-39. 